\title{
Awareness of Chronic Kidney Disease Evaluated Using Validated Questionnaire in Minia Governorate Public \\ Basma Fathy ${ }^{1}$, Hussien Se'eda ${ }^{2}$, Tarek Mohamed Fayez ${ }^{2}$, Mahmoud Ali Elshinawy ${ }^{2}$, Arwa Ashraf ${ }^{2}$, Asmaa Yasser ${ }^{2}$, Elham Mohamed ${ }^{2}$, Esraa Mohamed, Sara Adel ${ }^{2}$ \\ ${ }^{1}$ Internal medicine Department, Nephrology Unit, Faculty of Medicine, Minia University, Egypt \\ ${ }^{2}$ Student in $6^{\text {th }}$ grade, Faculty of Medicine, Minia University, Egypt \\ *Corresponding author: Basma Fathy, Mobile: (+20) 01003746052, E-Mail: basma.fathi@mu.edu.eg
}

\begin{abstract}
Background: Awareness and education of kidney disease has an impact on its effective management and will reduce the economic and public health burden.

Objective: We conducted a cross-sectional descriptive study to assess the level of awareness, knowledge and common risk factors of CKD in the community to plan to preventive modalities.

Patients and methods: We used a pretested validated questionnaire to gather information about sociodemographic knowledge and risk factors of CKD from 464 residents aged $>18$ years.

Results: A total of 464 residents completed this study with a median age of 30 years, $50.5 \%$ of them were females. The mean knowledge score of chronic kidney disease (CKD) was relatively poor as it was $13.12 \% \pm 3.95$. Only $48.6 \%$ could mention at least one function of the kidneys with $66.4 \%$ agreeing with that certain medications can help to slow-down the worsening of chronic kidney disease. A laboratory test for kidney function was known by $75.9 \% .92 .9 \%$ and $17.2 \%$ believe that CKD can be cured by spiritual means and herbal concoctions respectively. Abdominal obesity and excessive stress were seen in $64.7 \%$ and $45.5 \%$ respectively. Hypertension was seen in $56.5 \%$ while diabetes mellitus was found in $57.1 \%$ as risk factors for chronic kidney disease.

Conclusion: Efforts should be made to increase the public knowledge of CKD in Minia, Egypt as it was relatively poor that may be achieved by increasing awareness, education of people about CKD and how to prevent or regress its risk factors.
\end{abstract}

Keywords: Chronic kidney disease, Cross-sectional study, Public knowledge.

\section{INTRODUCTION}

Chronic kidney disease (CKD) is defined as abnormalities of kidney structure or function for more than 3 months, with inferences on health ${ }^{(\mathbf{1})}$. The rapidity of climbing CKD the ladder in the lists of causes of global death was alarming ${ }^{(2)}$. The prevalence of CKD is increasing in Egypt and is likely to continue to rise as risk factor such as diabetes mellitus and hypertension are increasing in the coming years ${ }^{(3,4)}$. Also, the increasing incidence of infectious diseases leading to nephropathies may be another cause. The major challenge of CKD patients in developing countries is the presentation of most patients in an advanced stage which might be returned to a poor level of awareness and knowledge of the disease ${ }^{(5,6)}$.

In developed countries epidemiological studies have also shown a low level of awareness, knowledge and risk factors of CKD as in the United States (US), the awareness of CKD among people with glomerular filtration rate (GFR) $15-60 \mathrm{ml} / \mathrm{min}$ was $24.3 \%{ }^{(7)}$. While in Australia was only $2.8 \%{ }^{(8)}$. In a study among African Americans, only $23.7 \%$ knew at least one laboratory test for kidney disease and $<3 \%$ agreed that CKD is an important health condition ${ }^{(9)}$. Improving quality of life and increasing productivity will be the inevitable result of early identification and creation of awareness of risk factors ${ }^{\mathbf{( 1 0 )}}$. Information on awareness of CKD in Egypt is scanty; this study was conducted to determine the level of CKD awareness and knowledge in order to organize preventive modalities using the information gathered from our population.

\section{PATIENTS AND METHODS}

This is a cross-sectional descriptive study conducted in Minia community; it was conducted between January and February 2020. Our medical students run outpatient clinics in Minia University Hospital and other areas in our community on regular intervals. A pretested validated questionnaire was used to draw information on sociodemographic awareness, knowledge and beliefs about CKD from 464 participants aged $>18$ years.

Interviewers were trained, and questionnaires were administered in the local language. The pretested validated questionnaire was divided into 5 sections and included a total of 24 evidence-based questions on the physiology of the kidneys, 'Kidney Health Check'(11), risk factors for CKD ${ }^{(12)}$ and signs \& symptoms of advanced CKD or kidney failure. With the multiplechoice options 'True', 'False' and 'I don't know'.

Correct responses were given a score of 1 and incorrect responses including the option 'I don't know' were given a score of 0 . Reliability of validated questionnaire was measured by calculating the Cronbach's alpha. Permission to enter the hospital was taken from the hospital leader. 
Ethical consent:

An approval of the study was obtained from Minia University Academic and Ethical Committee. Informed written consent was taken from each of the participants who were visited in their homes. This work has been carried out in accordance with The Code of Ethics of the World Medical Association (Declaration of Helsinki) for studies involving humans.

\section{Statistical analysis}

Multivariate analyses were performed using oneway ANOVA and independent t-tests, as appropriate, to compare the effect of participants' sociodemographic characteristics on the CKD knowledge score. SPSS Statistics for Windows, version 23 was used to perform all the statistical analyses. $\mathrm{P}$ value $<0.05$ was considered significant.

\section{RESULTS}

Sample of 464 participants were included in the analysis, and table (1) showed participants' characteristics.

Table (1): Participant characteristics

\begin{tabular}{|l|l|c|c|}
\hline \multicolumn{2}{|c|}{ Variable } & N & \% \\
\hline \multicolumn{2}{|l|}{ Total } & 464 & 100 \\
\hline Age Median (IQR) & 30.0 & $(22-40)$ \\
\hline \multirow{4}{*}{ Age Groups } & $\mathbf{1 8}$ to 29 & 231 & 49.8 \\
\cline { 2 - 4 } & $\mathbf{3 0}$ to 49 & 177 & 38.1 \\
\cline { 2 - 4 } & $\mathbf{5 0}$ & 56 & 12.1 \\
\hline \multirow{4}{*}{ Gender } & Female & 239 & 50.5 \\
\cline { 2 - 4 } & Male & 225 & 48.5 \\
\hline \multirow{3}{*}{$\begin{array}{l}\text { Occupation } \\
(\text { n = 464) }\end{array}$} & Professional & 44 & 9.5 \\
\cline { 2 - 4 } & Clerk & 94 & 20.3 \\
\cline { 2 - 4 } & Worker & 76 & 16.4 \\
\cline { 2 - 4 } & Don't work & 250 & 53.9 \\
\hline \multirow{3}{*}{ Residence } & Rural & 204 & 44.0 \\
\cline { 2 - 4 } & Urban & 260 & 56.0 \\
\hline \multirow{3}{*}{ Education } & Illiterate & 49 & 10.6 \\
\cline { 2 - 4 } & Primary & 40 & 8.6 \\
\cline { 2 - 4 } & Secondary & 125 & 26.9 \\
\cline { 2 - 4 } & Post-Secondary & 249 & 53.7 \\
\hline
\end{tabular}

As shown in figure (1), the men knowledge score of Minia public was $13.12 \pm 3.95$ with values ranging from 0 to $22.45 \%$ of the participants had knowledge scores less than 11 .

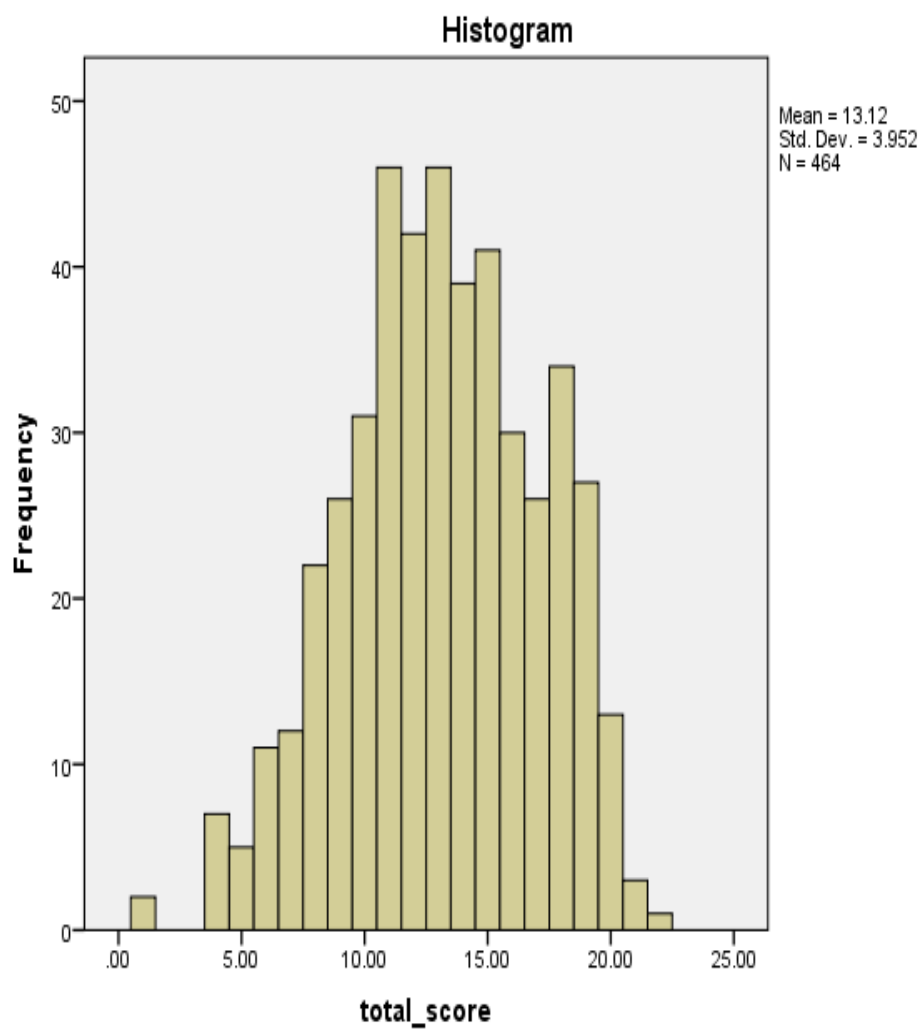

Figure (1): Distribution of the chronic kidney disease knowledge scores of Minia public

Most participants knew that kidneys make urine $(77.2 \%)$ and clean blood (68.3\%). However, few identified that kidneys help to maintain blood pressure (BP) $(46.6 \%)$ and keep the bones healthy (26.7\%). Many participants identified diabetes $(57.1 \%)$, but hypertension $(65.5 \%)$ was more frequently recognized as risk factors.

Most participants knew that urine (92.9\%), blood (75.9\%) tests help to determine the kidney health and $47.8 \%$ people knew that BP monitoring also helps in evaluating kidney health. Fortunately, only $17.2 \%$ knew that herbal supplements are effective in treating CKD and just over $66.4 \%$ knew that medication could help in delaying the progression of CKD (Table 2). 
Table (2): The percentage of participants with correct responses to individual items on the questionnaire

\begin{tabular}{|c|c|c|c|}
\hline \multirow[t]{2}{*}{ No } & \multirow[t]{2}{*}{ Question } & \multicolumn{2}{|c|}{$\begin{array}{l}\text { Correct } \\
\text { responses } \\
(\%)\end{array}$} \\
\hline & & $\mathbf{N}$ & $\%$ \\
\hline 1 & $\begin{array}{l}\text { A person can lead a normal life with } \\
\text { one healthy kidney. }\end{array}$ & 394 & 84.9 \\
\hline 2 & $\begin{array}{l}\text { Herbal supplements can be effective in } \\
\text { treating chronic kidney disease. }\end{array}$ & 80 & 17.2 \\
\hline 3 & $\begin{array}{l}\text { Certain medications can help to slow- } \\
\text { down the worsening of chronic kidney } \\
\text { disease. }\end{array}$ & 308 & 66.4 \\
\hline \multirow[t]{2}{*}{ No } & \multirow[t]{2}{*}{$\begin{array}{l}\text { Question } 2 \text { What functions do the } \\
\text { kidney perform in our body? }\end{array}$} & \multicolumn{2}{|c|}{$\begin{array}{l}\text { Correct } \\
\text { responses } \\
(\%)\end{array}$} \\
\hline & & $\mathbf{n}$ & $\%$ \\
\hline 4 & The kidneys make urine. & 358 & 77.2 \\
\hline 5 & The kidneys clean blood. & 317 & 68.3 \\
\hline 6 & $\begin{array}{l}\text { The kidneys help to keep blood sugar } \\
\text { level normal. }\end{array}$ & 191 & 41.2 \\
\hline 7 & $\begin{array}{l}\text { The kidneys help to maintain blood } \\
\text { pressure. }\end{array}$ & 216 & 46.6 \\
\hline 8 & $\begin{array}{l}\text { The kidneys help to breakdown } \\
\text { protein in the body. }\end{array}$ & 148 & 31.9 \\
\hline 9 & $\begin{array}{l}\text { The kidneys help to keep the bones } \\
\text { healthy. }\end{array}$ & 124 & 26.7 \\
\hline \multirow[t]{2}{*}{ No } & \multirow[t]{2}{*}{$\begin{array}{l}\text { Question } 3 \text { Which of the following } \\
\text { are commonly used to determine } \\
\text { the health of your kidneys? }\end{array}$} & \multicolumn{2}{|c|}{$\begin{array}{l}\text { Correct } \\
\text { responses } \\
(\%)\end{array}$} \\
\hline & & $\mathbf{n}$ & $\%$ \\
\hline 10 & A blood test. & 352 & 75.9 \\
\hline 11 & A urine test. & 431 & 92.9 \\
\hline 12 & A faecal (poo) test. & 242 & 52.2 \\
\hline 13 & Blood pressure monitoring. & 222 & 47.8 \\
\hline \multirow[t]{2}{*}{ No } & \multirow[t]{2}{*}{$\begin{array}{l}\text { Question } 4 \text { What are the risk } \\
\text { factors for chronic kidney disease? }\end{array}$} & \multicolumn{2}{|c|}{$\begin{array}{l}\text { Correct } \\
\text { responses } \\
(\%)\end{array}$} \\
\hline & & $\mathbf{n}$ & $\%$ \\
\hline 14 & Diabetes. & 265 & 57.1 \\
\hline 15 & Being female. & 114 & 25.6 \\
\hline 16 & High blood pressure. & 262 & 56.5 \\
\hline 17 & $\begin{array}{l}\text { Heart problems such as heart failure or } \\
\text { heart attack. }\end{array}$ & 162 & 34.9 \\
\hline 18 & Excess stress. & 211 & 45.5 \\
\hline 19 & Obesity. & 300 & 64.7 \\
\hline \multirow[t]{2}{*}{ No } & \multirow{2}{*}{$\begin{array}{l}\text { Question } 5 \text { What are the signs and } \\
\text { symptoms that a person might have } \\
\text { if they have advanced chronic } \\
\text { kidney disease or kidney failure? }\end{array}$} & \multicolumn{2}{|c|}{$\begin{array}{l}\text { Correct } \\
\text { responses } \\
(\%)\end{array}$} \\
\hline & & $\mathbf{n}$ & $\%$ \\
\hline 20 & $\begin{array}{l}\text { Water retention (excess water in the } \\
\text { body). }\end{array}$ & 390 & 84.1 \\
\hline 21 & Fever. & 100 & 21.6 \\
\hline 22 & Nausea/vomiting. & 278 & 59.9 \\
\hline 23 & Loss of appetite. & 284 & 61.2 \\
\hline 24 & Easy fatigability & 337 & 72.6 \\
\hline
\end{tabular}

Table (3) showed the results of the correlation analysis performed using Pearson's correlation between participants' characteristics and total score. The analysis of variance showed significant associations between the CKD knowledge score and sociodemographic variables, such as education, occupation and residence $(\mathrm{p}<.002,0.014$ and 0.000 respectively).

Table (3): Correlation of knowledge score among study participants

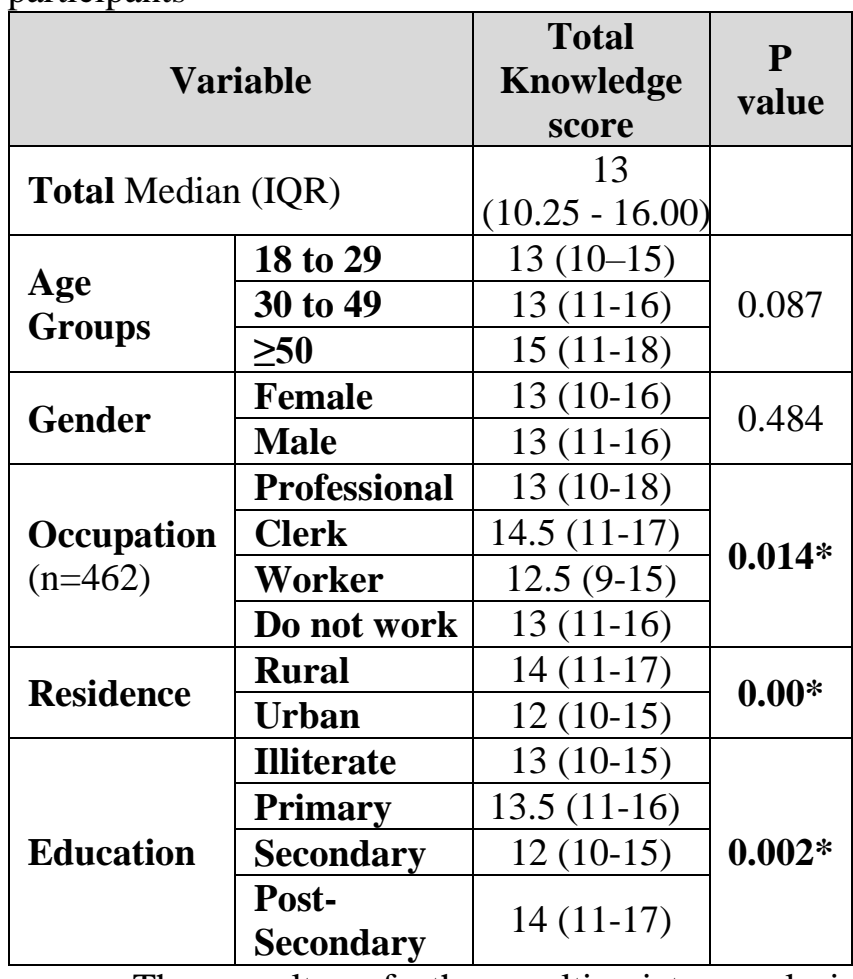

The results of the multivariate analysis performed using independent t-tests between participants' characteristics and the total score showed that there was a significant positive correlation of knowledge score with the level of education and urban residence (Table 4).

Table (4): Multivariate analysis between different variables and knowledge score

\begin{tabular}{|l|c|c|}
\hline \multicolumn{1}{|c|}{ Variable } & Correlation Coefficient & P value \\
\hline Age Groups & 0.085 & 0.068 \\
\hline Gender & 0.033 & 0.484 \\
\hline Occupation & -0.071 & 0.127 \\
\hline Residence & $\mathbf{- 0 . 2 1 8}$ & $\mathbf{0 . 0 0 0}^{*}$ \\
\hline Education & $\mathbf{0 . 1 3 1}$ & $\mathbf{0 . 0 0 5} *$ \\
\hline *Correlation is significant at the 0.01 level (2-tailed). \\
\hline \multicolumn{2}{|l}{}
\end{tabular}

\section{DISCUSSION}

The results of our study show poor understanding of CKD among Minia governorate public. Participants in our study had relatively limited knowledge of the physiological role of the kidneys especially knowledge about CKD risk factors as just more than half of the participants correctly identified hypertension as risk factor for CKD (56.5\%) although this percentage was higher than that reported in a study on Australian public by Gheewala et al. ${ }^{(13)}$ as it was $38.3 \%$. A study in Hong Kong reported that $43.8 \%$ of participants knew that hypertension can cause kidney disease (14). A cross-sectional study in South-West Nigeria found that $54.7 \%$ believed that hypertension was a CKD risk factor ${ }^{(\mathbf{1 5})}$ what was near to our results. On the other hand, the percentage of participants who 
correctly identified diabetes as a risk factor in this study $(57.1 \%)$ was higher than the results reported by Chow et al. ${ }^{(14)}$ and Oluyombo et al. ${ }^{(15)}$ which were $12.7 \%$ and $49.0 \%$ respectively, but was lesser than the percentage in the study of Gheewala et al. ${ }^{(13)}$, which was $60.6 \%$. There is more need to improve awareness about $\mathrm{BP}$, its regular monitoring and its association with CKD as well as diabetes among the public.

About $66.4 \%$ of the participants knew that medication can help to slow the worsening of CKD. This suggests that the understanding of the treatment of kidney failure is relatively higher in Minia governorate than the Australian public which was 50\%. In addition, $82.2 \%$ of participants knew that herbal supplements are ineffective in treating CKD in comparison of $23.4 \%$ and $44.6 \%$ in the studies by Gheewala et al. ${ }^{(13)}$ and Oluyombo et al. ${ }^{(15)}$ respectively. Moreover, the mean knowledge score in our study was $13.12 \pm 3.95$ that was higher than the Australian study, which was $10.34 \pm 5.0$. The relatively higher results than others might be explained by the higher incidence of CKD and ESRF in our country. The correlation analysis showed that CKD knowledge score increased with a higher level of education ( $p$ value $<0.005$ ). This is consistent with the findings of other studies ${ }^{(14,15)}$.

Additionally, our result showed that participants who live in urban areas had higher CKD knowledge scores than who live in rural areas ( $p$ value $<0.000$ ) that might be attributed to that people who have lived in urban areas may obtain health related information and implementing healthy lifestyles more than there were lived in rural areas ${ }^{(16-19)}$. The KHACARI guidelines recommend that physicians should provide early CKD education to patients with CKD risk factors as this may prevent CKD development and progression ${ }^{(20)}$.

Creating questionnaire that can produce valid and reliable data is a complex process, so, we used a previously used validated one. It is acknowledged that the sample may not have been truly representative of the general public. Further studies should be made on all Egyptian public to evaluate the total score of knowledge on the level of our country as a whole, which can further assist in improving the CKD knowledge of Egyptian public.

\section{CONCLUSIONS}

The level of awareness and knowledge of kidney disease is relatively low. So, Efforts should be made to improve level of education of CKD, the burden of it and finding solutions to reduce its related risk factors in our community.

Financial support and sponsorship: Nil.

Conflict of interest: Nil.

\section{REFERENCES}

1. KDIGO (2012): Clinical Practice Guideline for the Evaluation and Management of Chronic Kidney Disease. Pp: 1- 163.https://kdigo.org/wp-

content/uploads/2017/02/KDIGO_2012_CKD_GL.pdf

2. Bikbov B, Perico N, Remuzzi G (2014): Mortality landscape in the global burden of diseases, injuries and risk factors study. Eur J Intern Med., 25: 1-5.

3. Stanifer J, Jing B, Tolan S et al. (2014): The epidemiology of chronic kidney disease in sub-Saharan Africa: A systematic review and meta-analysis. Lancet Glob Health, 2: 174-81.

4. Mathers C, Loncar D (2006): Projections of global mortality and burden of disease from 2002 to 2030. PLoS Med., 3: 442-46.

5. Obrador G, Garcia-Garcia G, Villa A et al. (2010): Prevalence of chronic kidney disease in the Kidney Early Evaluation Program (KEEP) Mexico and comparison with KEEP US. Kidney Int Suppl., 116: 2-8.

6. Vassalotti J, Li S, McCullough P et al. (2010): Kidney early evaluation program:A community-based screening approach to address disparities in chronic kidney disease. Semin Nephrol., 30: 66-73

7. Coresh J, Byrd-Holt D, Astor B et al. (2005): Chronic kidney disease awareness, prevalence, and trends among U.S. adults, 1999 to 2000. J Am Soc Nephrol., 16: 180-8.

8. White S, Polkinghorne $\mathrm{K}$, Cass A et al. (2008): Limited knowledge of kidney disease in a survey of AusDiab study participants. Med J Aust., 188: 204-208.

9. Waterman A, Browne T, Waterman B et al. (2008): Attitudes and behaviors of African Americans regarding early detection of kidney disease. Am J Kidney Dis., 51: 554-62.

10. Benson B, Storey E, Huntington $\mathrm{C}$ et al. (2008): The Economic Impact of Prevention. Centre for Public Health and Health Policy. Connecticut, University of Connecticut Health Center and University of Intern Med., 168: 2268-75.

11. Chronic Kidney Disease (CKD) Management in General Practice (2017): Guidance and clinical tips to help identify, manage and refer patients with CKD in your practice (3rd edition). Kidney Health Australia, Melbourne. Pp: 1-56. https://www.klmc.net. au /pdf/ckd-management.pdf

12. Australian Institute of Health and Welfare (2015): Cardiovascular disease, diabetes and chronic kidney diseaseAustralian facts: risk factors. Cardiovascular, diabetes and chronic kidney disease series no. 4. Cat. No. CDK 4. Canberra: AIHW. Pp: 1-108. https://www.aihw.gov.au/reports/heart-stroke-vasculardisease/cardiovascular-diabetes-chronic-kidneyprevalence/contents/table-of-contents

13. Gheewala P, Peterson G, Tabish $S$ et al. (2018): Public knowledge of chronic kidney disease evaluated using a validated questionnaire: a cross-sectional study. BMC Public Health, 18: 371-76.

14. Chow K, Szeto C, Kwan B et al. (2014): Public lacks knowledge on chronic kidney disease: telephone survey. Hong Kong Med J., 20 (2): 139-44.

15. Oluyombo R, Ayodele O, Akinwusi P et al. (2016): Awareness, knowledge and perception of chronic kidney disease in a rural community of south-West Nigeria. Niger J Clin Pract., 19 (2): 1619.

16. Li J, Berkowitz Z, Richards T et al. (2013): Shared decision making in prostate-specific antigen testing with men older than 70 years. J Am Board Fam Med., 26 (4): 401-8.

17. Begashaw B, Tessema F, Gesesew $H$ (2016): Health care seeking behavior in Southwest Ethiopia. PLoS One, 11 (9): 161-65.

18. Chen Y, Sun G, Guo X et al. (2017): Factors affecting the quality of life among Chinese rural general residents: a cross-sectional study. Public Health, 146: 140-7.

19. Streiner D, Norman $\mathbf{R}$ (2008): Health measurement scales: a practical guide to their development and use. 4th ed. Oxford: Oxford University Press. https://global.oup.com/ academic/product/health-measurement-scales-

9780199685219 ?cc $=$ us \& lang $=$ en $\&$

Johnson D, Atai E, Chan M et al. (2013): KHA-CARI guideline: early chronic kidney disease: detection, prevention and management. Nephrology (Carlton Vic), 18 (5): 340-50. 